\author{
Tapio S. Katko
}

\title{
The role of domestic gardens in urban green infrastructures and its potential for scalability
}

The theme of the dissertation "The role of domestic gardens in urban green infrastructures and its potential for scalability" is undoubtedly very relevant and topical. It connects with one of the most challenging areas in urban planning and development in Finland as well as internationally and is also linked with climate change.

Among others, urban densification is one of the most important policies in Finland and is based on many good arguments. However, this phenomenon has also some limitations such as the need for better stormwater management and the overall management of green infrastructure through water, vegetation and soil. Another limitation for densification is obviously the need for adequate recreational areas.

The overarching aim of the thesis is to enhance the role of private gardens in urban Green Infrastructure (GI) and develop their potential to better support the city-scale green space system through the practices of sustainable urban planning and design.

This dissertation has three more specific aims, which form a scalable continuum. The first aim, which relates to the plot scale and its gardens, is to map the current situation, both in terms of functions and surface coverage. This initial scale is assumed to be the core of Green Infrastructure in Low Density Housing areas, and the aim is formulated as follows:

AIM A: To present the state-of-the-art of private domestic gardens for green infrastructure.

AIM B: To develop detail-scale integration between water and vegetation for local conditions.

AIM C: To improve garden-scale Green Infrastructure to enhance up-scaled Green Infrastructure.

Each of these aims is addressed through specific research questions.

This article-based doctoral dissertation manuscript has six related papers. Four of them are published in peer review journals: I Land Use Policy, II Architectural Research in Finland, V and VI Sustainability. In addition, two peer reviewed conference papers are included as papers III, and IV. These altogether do meet more than well the requirement of at least three full-length articles.

The table of contents of the synthesis part (called also summary or compiling part) is well balanced having six major chapters plus References. In the references of the synthesis 
part altogether 126 references are cited. Those in the published papers are altogether 205 references, although I have not checked obvious repetitions.

In any case, the coverage of literature is substantial. The candidate is the main author of all the included papers, while having co-authors in two of the papers. The independent contribution to the research is thus clearly demonstrated. The literature cited covers also developments in other parts of Europe, the USA, and Australia, although the focus of the study is on Finland.

The multifunctionality of private gardens in Low Density Housing areas was studied via literature review, followed by a two-year experiment in a test field to explore the functioning of the Green Infrastructure's core system through the concept of bioretention. An iterative design process to improve the performance of private gardens on different scales used a variation of the research by design method.

The results provide knowledge for urban planning, garden design and landscape construction that work mainly at different scales of Green Infrastructure. Overall, the papers and the synthesis part form a well-balanced integrity although we can always argue also for possible lack of adequate integration in this type of article-based dissertation.

This dissertation concentrates on scalable Green Infrastructure in Low Density Housing areas and the associated gardens. The study recognizes the dynamic system of water, soil, and vegetation as the Green Infrastructure's core system.

The functioning of the core system was explored by developing bioretention details for local conditions that provided technical details for the practices of stormwater management but also a more conceptual knowledge on the Green Infrastructure's core system that is essential for the development and management of Green Infrastructure at all scales.

The dissertation proposes that garden scale Green Infrastructure may be enhanced by approaching the Green Infrastructure's core system as a continuum to better integrate green and grey components of the urban environment.

Gardens have an interconnected set of ecological, economic, and social roles in Green Infrastructure. This multifunctional role can support the design and management of gardens and the locations of pervious and impervious areas both during the planning and design phases but also during the on-going choices made by garden owners as part of their maintenance works.

The impervious coverage of Finnish single-family house plots is determined in urban planning through the definition of housing densities and the locations of buildings; in architectural design through roof size and entrances defining the required passages; and in garden design through the selection of surface materials in the garden area and the design of the garden itself. Increase in housing density decreases pervious coverage that relates to soil connected vegetation coverage. However, the type of vegetation seems to change when housing density increases as the proportion of lawns decreases in favour of plantings.

The interaction between soil, water, and vegetation may be improved by approaching these elements in a more integrative way and by system thinking. Thus, the system integrated by soil, water, and vegetation takes place in all parts of the garden and not only in specially designed constructions such us Sustainable Urban Drainage System. Yet, according to the study, the design of the garden needs to be tailored to benefit local soil and gravel materials, to support vegetation growth, and most importantly perceive the garden as part of a bigger system.

Six criteria to improve the planning and design of scalable Green Infrastructure are presented, forming a very solid and relevant synthesis of the findings. The dissertation by Outi Tahvonen argues for the integrative design of stormwater management and plantings at plot scale instead of dividing its design in disconnected phases between uncoordinated specialists. The theoretical framework of the study is strong. 
As for research methods and strategies used, the commonly required scientific criteria are met. The approach is based also on practical experience. The time spent for this dissertation is longer than normal which is largely explained by the part-time involvement of the doctoral candidate and by the diverse nature of the issues addressed in the developed research and by the inclusion of field experiments.

The manuscript has very good and informative illustrations which, to my mind, is well in line with landscape architecture. The English text is well written and fluent. Only a few typing errors and some limitations in one graph could be identified. The synthesis part is well made including the fact the candidate has shown balanced consideration of repeating only a few, major graphs published in the original papers.

The limitations of the study were openly and critically discussed and two main avenues for further research were proposed. The questions raised in the preliminary assessment have been well-answered and taken into account except for perhaps a few minor cases. Namely, the historical background of Green Infrastructure development in Finland first in the late 1970s and 1980s and more recently in the 2010s could have shortly been included to provide a chronological perspective.

During the public defence, the candidate was able to reply well to all questions raised and continue actively the discussion. Among others, she explained the reasons to select the title used, some of the used concepts in Finnish language, major changes that happened during the study and their reasons, major strengths and weaknesses of the study as well as views on the need for further regulations in terms of top-down and bottom-up approaches. The 20 minutes lectio praecursoria was well prepared and presented with very good and informative illustrations including some key messages also in Finnish in deference to the audience.

On the whole, the author has made a significant independent contribution to the findings, and the dissertation has clearly scientific merits and new findings.

Doctoral dissertation: Tahvonen, O. (2019) Scalable green infrastructure and the water, vegetation and soil system. Scaling up from Finnish domestic gardens. Aalto University publication series Doctoral Dissertations, 180/2019. https://aaltodoc.aalto.fi/handle/123456789/40764 